\title{
Diagnostics of Pulsed Beams of Electrons, Ions, and Atoms (Review)
}

\author{
A. I. Pushkarev ${ }^{a, *}$, A. I. Prima ${ }^{a}$, Yu. I. Egorova ${ }^{a}$, and V. V. Ezhov ${ }^{a}$ \\ a Tomsk National Research Polytechnic University, \\ Tomsk, 634050 Russia \\ *e-mail: aipush@mail.ru
}

Received November 25, 2019; revised November 25, 2019; accepted December 21, 2019

\begin{abstract}
A review of methods for diagnosing the most important parameters of pulsed beams of electrons, ions, and accelerated atoms, such as the current density, fluence, total energy per pulse, the energy density distribution over the cross section, the composition of the beam, and its energy spectrum, is presented. The main attention is paid to the methods of diagnostics of beams intended for technological applications with a particle energy of $0.01-1 \mathrm{MeV}$ and an energy density of $0.1-10 \mathrm{~J} / \mathrm{cm}^{2}$. This paper contains a description of each diagnostic method, its scope of application, and systematic errors. The thermal imaging diagnostics of the total energy of a particle beam, the energy-density distribution over the cross section, the beam movement in the focal plane in a series of pulses, and the beam divergence during its transport to the target are considered. The time-of-flight diagnostics of ion beams is presented, which allows determining the beam composition, the fluence, and the energy spectrum of each type of ion in a beam of a complex composition (ions with different masses and degrees of ionization). The acoustic (thermoradiation) diagnostics based on the detection of acoustic waves, which are generated by a particle beam in a metal target by a piezoelectric transducer, is described.
\end{abstract}

DOI: $10.1134 / \mathrm{S} 0020441220030148$

\section{INTRODUCTION}

The impact of pulsed energy fluxes of gigawatt power, which provides heating and cooling of the surface layer of a processed item at a speed of $10^{8}-10^{9} \mathrm{~K} / \mathrm{s}$ (ultrafast quenching) at a pressure of $10^{8} \mathrm{~Pa}$ (superpower forging) [1, 2], allows forming structures in the surface layers whose composition and nanometer dimensions cannot be obtained by other methods. As a result, the properties of materials, such as the hardness, strength, and wear resistance are improved; the performance characteristics of products made of such materials are improved as well. Electron and ion beams are also used for simulating irradiation of structural materials in the study of their radiation resistance [3-5].

To control the parameters of pulsed beams that are intended for technological applications (with a particle energy of $0.01-1 \mathrm{MeV}$ and a beam energy density of $0.1-10 \mathrm{~J} / \mathrm{cm}^{2}$ ), thermal imaging diagnostics (TID) (to measure the total energy and energy-density distribution over the cross section, the beam movement in the focal plane in a series of pulses, and the beam divergence during its transport to the target), time-offlight (TOF) diagnostics (to measure the composition of the ion beam, the fluence, and the energy spectrum of each type of ion in a beam of complex composition), a Faraday cup (to measure the total electron- beam current and the ion-current density), and acoustic diagnostics (for measuring the cross-sectional energy-density distribution) are used.

\section{THERMAL IMAGING DIAGNOSTICS OF ION AND ATOMIC BEAMS}

For an amplitude of an ion-current density pulse of $200-300 \mathrm{~A} / \mathrm{cm}^{2}$ and a pulse duration of $100-150 \mathrm{~ns}$ (a Gaussian pulse), the charge density per pulse is 15$20 \mu \mathrm{C} / \mathrm{cm}^{2}$. This corresponds to a fluence of singly charged ions per pulse of $(0.9-1.3) \times 10^{14} \mathrm{~cm}^{-2}$. The range of ions with energies of $200-300 \mathrm{keV}$ in metals does not exceed $1 \mu \mathrm{m}$, while their concentration in the near-surface layer is below $10^{18} \mathrm{~cm}^{-3}$ (the concentration of Fe atoms is $8.5 \times 10^{22} \mathrm{~cm}^{-3}$ ). In this case, the energy density of a high-power ion beam (HPIB) is 3$5 \mathrm{~J} / \mathrm{cm}^{2}$, and the main factor that determines changes in the properties of a product when exposed to a gigawatt-power ion beam is a thermal effect but not the ion implantation [6]. Therefore, it is primarily important to control the energy density of a HPIB to optimize the mode of processing products with such a beam, while the calorimetric diagnostics is the main technique for studying the parameters of pulsed ion beams and accelerated atoms [7]. 


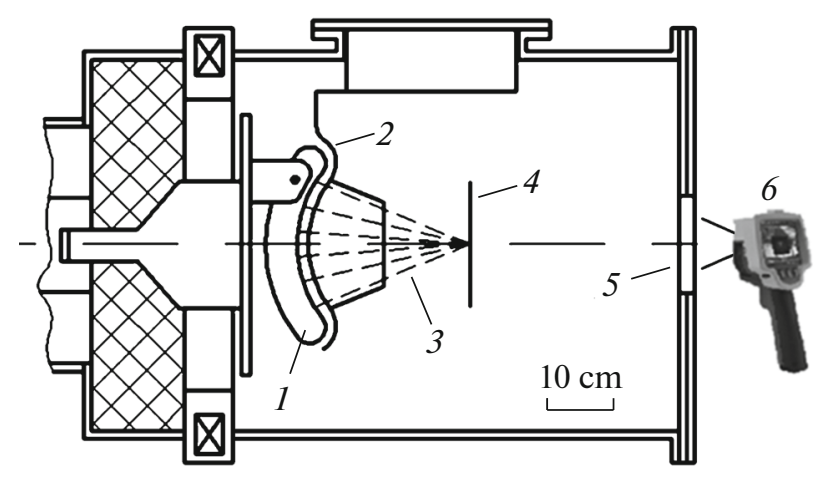

Fig. 1. A diagram of measurements of the HPIB energy density distribution: (1) anode; (2) cathode; (3) ion beam; (4) target; (5) optical window; and (6) thermal imager.

A comparative analysis of the correctness of the beam diagnostics according to the amplitude of ioncurrent density pulses and the HPIB energy density was presented in [8]. The influence of the ion-energy spread, ion beam composition, accelerated atoms, locality of the diagnostics, and other factors on the HPIB diagnostics error was analyzed. It was shown that energy-density measurements provide more correct and complete information that does not contain systematic errors. TID is widely used to study the parameters of pulsed beams of electrons, ions, and accelerated atoms.

The calorimetric method was used for measuring the parameters of HPIBs for the first time in 1976 by the English scientists, Christodoulides and Freeman [9]. The use of a thermal imager to measure the HPIB energy-density distribution was proposed in 1997 by Davis et al. [10]. These studies have shown that TID of parameters of pulsed ion beams and accelerated atoms is an effective on-line monitoring method [7, 11, 12]. It allows one to measure the total energy of a beam and the energy-density distribution on a target in a single pulse, optimize the operation of an ion source, and control the target irradiation mode.

The spatial resolution of TID is $1-2 \mathrm{~mm}$; the sensitivity of a typical thermal imager provides registration of a thermal imprint in a single pulse at an energy density that exceeds $0.02 \mathrm{~J} / \mathrm{cm}^{2}$. The correct use of the thermalimaging technique when monitoring the HPIB parameters requires that the contribution of electrons, plasma, and other factors to the target heating be taken into account [12].

\subsection{The Technique for Meausring the HPIB Energy Density}

The TID of the HPIB parameters is conducted according to the thermal imprint on a metal target using a thermal imager. The recording scheme is shown in Fig. 1. A stainless-steel [7] or titanium [10, 11] foil is used as the target. Among the widely used structural materials, stainless steel stands out for its low heat capacity and thermal conductivity, which are important for TID. To increase the target emissivity coefficient, its back (from the ion beam) side is coated with a black dull paint $(\varepsilon=0.95)$. The life of such a target is $10^{3}-10^{4}$ HPIB pulses with an energy density of up to $15 \mathrm{~J} / \mathrm{cm}^{2}$.

The generation of the HPIB and target irradiation occur in a diode chamber at a pressure of below $10 \mathrm{~Pa}$; therefore, the thermal imprint of the beam is registered through the output window, which is located on a flange of the diode chamber. A flat plate made of calcium fluoride $\left(\mathrm{CaF}_{2}\right)$, or $\mathrm{NaCl}, \mathrm{ZnSe}, \mathrm{BaF}_{2}$ is used for the window. Calcium fluoride and other optical materials have incomplete transmissions in the operating spectral range of the thermal imager $(7-14 \mu \mathrm{m})$, and the readings of the thermal imager that registers the heat flux, which passes through the optical window, must be corrected. Studies have shown that the coefficient of attenuation of thermal radiation by the $\mathrm{CaF}_{2}$ and $\mathrm{BaF}_{2}$ windows changes slightly with their prolonged use for registering a thermal imprint of an HPIB.

The amount of energy $E$, $\mathrm{J}$, that is liberated in a target during its irradiation is:

$$
E=c_{V} m \Delta T=c_{V} d \rho S \Delta T(x, y),
$$

where $c_{v}, \mathrm{~J} /(\mathrm{g} \mathrm{deg})$, is the specific heat; $S, \mathrm{~cm}^{2}$, is the area of the target; $d, \mathrm{~cm}$, is the target thickness; $\rho$, $\mathrm{g} / \mathrm{cm}^{3}$, is the density of the target material; and $\Delta T$, $\mathrm{deg}$, is the target temperature increment.

When an infrared image (IR image) is recorded through the optical window, the HPIB energy density $J(x, y), \mathrm{J} / \mathrm{cm}^{2}$, is then equal to

$$
J(x, y)=\frac{E}{S}=K_{1} c_{V} d \rho \Delta T(x, y),
$$

where $K_{1}$ is the attenuation coefficient for thermal radiation in the optical window.

For a minimum temperature sensitivity of a Fluke Ti10 thermal imager of $0.2^{\circ} \mathrm{C}$, the minimum energy density for a $0.1-\mathrm{mm}$-thick stainless-steel target is $0.03 \mathrm{~J} / \mathrm{cm}^{2}$ for the $\mathrm{CaF}_{2}$ window and $0.01 \mathrm{~J} / \mathrm{cm}^{2}$ for $\mathrm{BaF}_{2}$.

After heating the front side of the target with an ion beam, the thermal imager measures the temperature of its back side. The time required to increase the temperature of the rear surface of the target by $50 \%$ of the maximum temperature can be estimated using the Parker method [13, 14]:

$$
\tau_{0.5}[\mathrm{~s}]=\frac{1.38 d^{2}}{\pi^{2} a},
$$

where $a, \mathrm{~m}^{2} / \mathrm{s}$ is the thermal diffusivity.

For a stainless-steel target with a thickness of $0.1 \mathrm{~mm}$ ( $a=1.5 \times 10^{-5} \mathrm{~m}^{2} / \mathrm{s}$ ), the heating time $\tau_{0.5}$ is at most $0.1 \mathrm{~ms}$. The results of calculating the target warm-up time, which corresponds to the temperature equalization over the thickness with a gradient below $0.02^{\circ}$ were presented in [15]. When the stainless-steel target 
thickness is less than $0.2 \mathrm{~mm}$, the warm-up time does not exceed $10 \mathrm{~ms}$. When using the Fluke Ti400 thermal imager in the video mode, the thermal imprint is registered on the target $0.1 \mathrm{~s}$ after the HPIB pulse generation (hardware delay). Therefore, the error of TID, which is caused by inhomogeneous heating of the target in thickness, is insignificant.

A delay in recording an HPIB IR image may cause an error in the results of TID due to the target cooling. When the thermal imager is operating in the video mode (usually 9 frames/s), the delay between the HPIB generation (with a pulse duration of $150 \mathrm{~ns}$ ) and the IR image registration does not exceed $0.1 \mathrm{~s}$.

Figure 2 shows the HPIB energy-density distribution in the vertical focal plane and the reduction of the target temperature at the point of the maximum heating during the target cooling. Since the ion source and target are in a vacuum, the target is cooled slowly; the temperature decreases by at most $2 \%$ within $0.2 \mathrm{~s}$. Thus, the error of TID that is caused by the target cooling is insignificant.

TID provides a high spatial resolution of the crosssectional HPIB energy-density distribution. A hole with a $3-\mathrm{mm}$ diameter was made in the target to evaluate this distribution (Fig. 3). TID made it possible to correctly register a decrease in the target temperature in the vicinity of the hole; the diagnostic resolution was $1-1.5 \mathrm{~mm}$. The energy density in the hole did not decrease to zero, since there was a source behind the target whose temperature was higher than the initial temperature of the target.

\subsection{The Expansion of the Measurement Range of Thermal Imaging}

It is of great interest to control the parameters of an HPIB with a high energy density that is necessary for sputtering a target or modifying it with shock recoil waves [2]. However, ablation of the target material limits the range of measurements using TID. A metal mesh that was installed in the drift and HPIB focus region was used to extend the measurement range in [10]. The measurement results were adjusted taking the mesh transparency into account (Fig. 4).

The HPIB energy density was measured in [10] by two methods: using TID (i.e., according to the energy density absorbed in the target) and the ion-current density (i.e., according to the total HPIB energy density, which is equal to the integral of the product of the ioncurrent density and the accelerating voltage over the pulse duration). The results show that for an energy density that exceeds $5 \mathrm{~J} / \mathrm{cm}^{2}$ (see Fig. 4) the transparency of the metal mesh decreases and the data obtained by two methods differ significantly. With a further increase in the HPIB energy density the discrepancy increases.

The transparency of the metal mesh may change due to the ablation plasma that overlaps the region between the mesh wires, especially when its optical
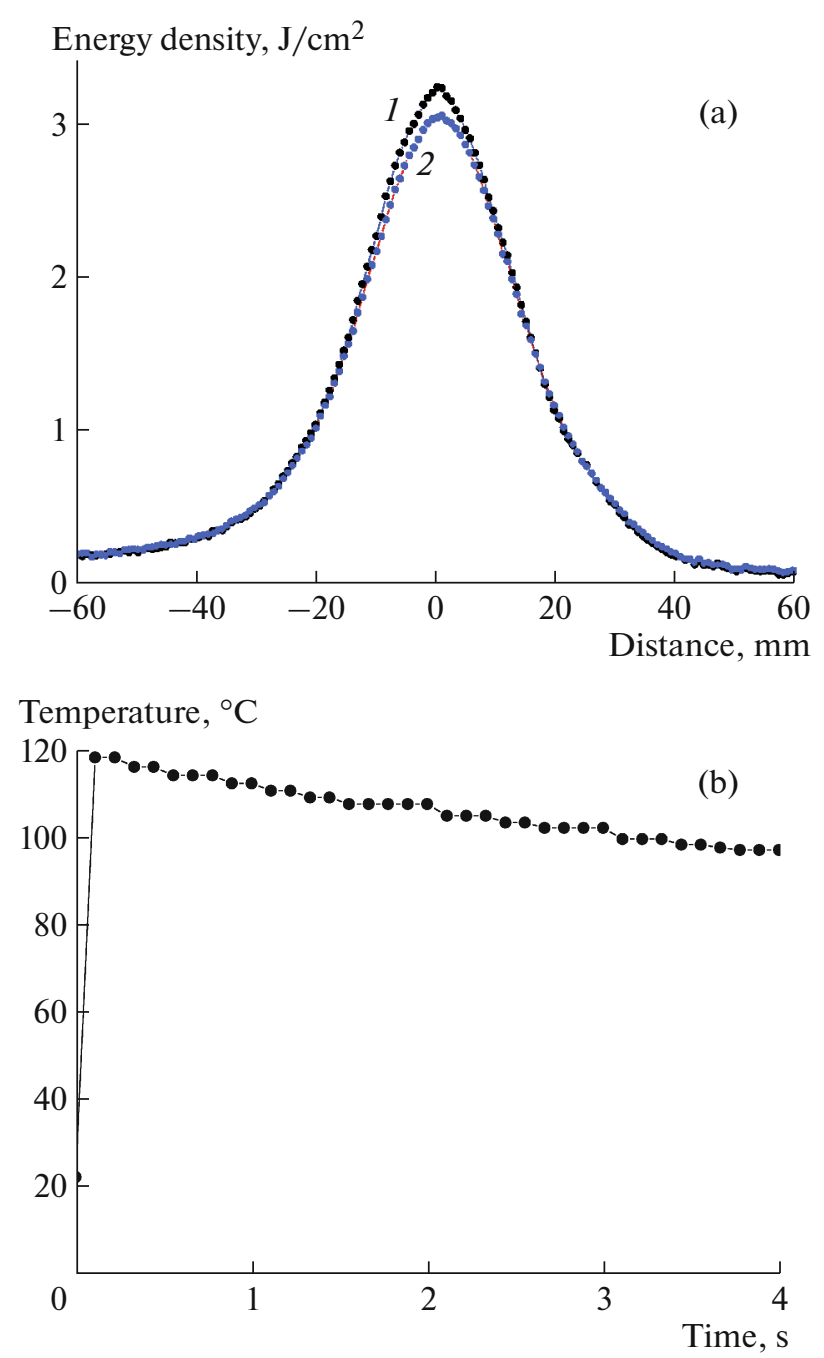

Fig. 2. (a) The HPIB energy-density distribution in the focal plane in the vertical direction (1) 0.1 and (2) $1 \mathrm{~s}$ after irradiation; (b) decrease (during heating) in the target temperature at the maximum heating point.

transparency is low. An error in measuring the ioncurrent density due to the overlap of the collimating hole of the Faraday cup by the ablative plasma was found in [16]. When using a metal grid to attenuate an HPIB, the beam may be additionally focused by its own spatial charge [17].

Another method for expanding the range of TID measurements is based on HPIB scattering after its passage through the collimating hole in the target $[7,10]$. When the ion beam is scattered after passing through the hole in the first target the energy density of the beam that falls on the second target (which is mounted at a distance of $10-20 \mathrm{~mm}$ behind the first target) is reduced to a level below the ablation threshold, which ensures that the correctness of measurements and allows calculation of the average energy density in the region of the hole in the first target. However, this method does not allow one to measure 
(a)

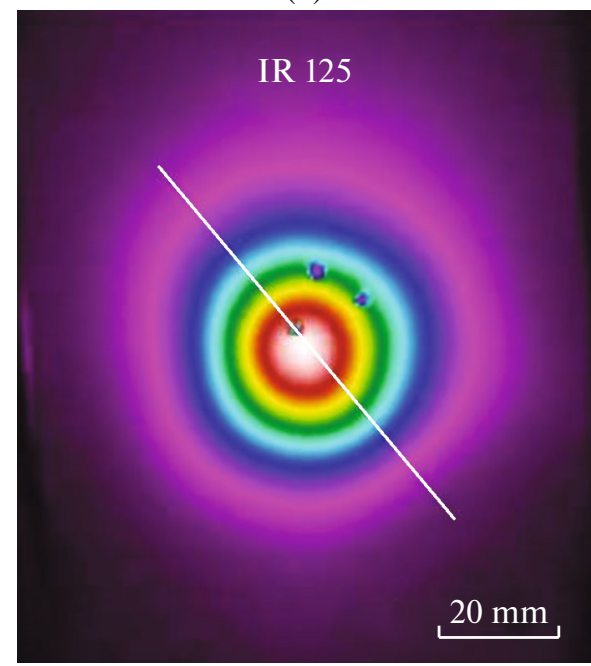

(b)

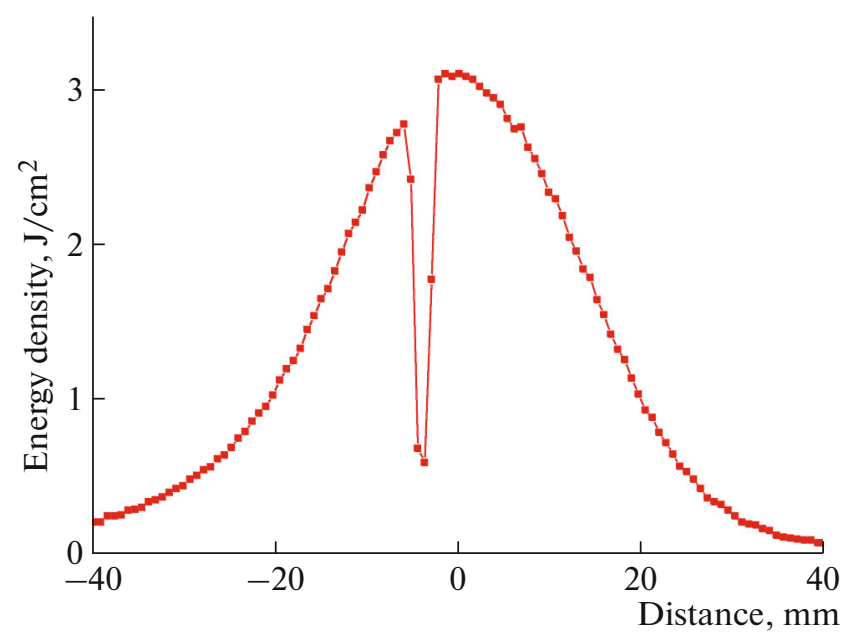

Fig. 3. (a) An HPIB infrared image and (b) the energy density distribution along the line in the IR image. The hole is $3 \mathrm{~mm}$ in diameter, $\mathrm{BaF}_{2}$ window.

the cross-sectional distribution of the HPIB energy density and determine its total energy. Moving the HPIB in the focal plane in a series of pulses introduces a significant error in this method.

Our studies have shown that the maximum energy density measured using TID significantly exceeds the ablation threshold of the target material (Fig. 5). This was observed for all the studied materials except for tungsten (Table 1) [18, 19].

Overheating $R, \%$, was calculated from the ratio

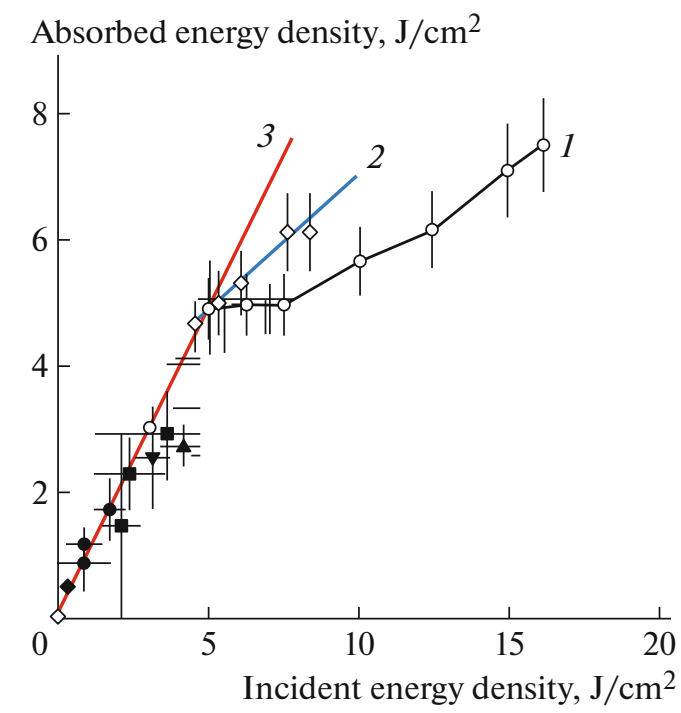

Fig. 4. The energy density measured using TID as a function of the total HPIB energy density: (1) without a grid on the target, (2) with a grid, and (3) the absorbed-energy density is equal to the total HPIB energy density [10].

$$
R=\frac{100\left(J_{\max }-J_{\mathrm{thr}}\right)}{J_{\mathrm{thr}}},
$$

where $J_{\max }$ is the HPIB energy density at the focus, and $J_{\mathrm{thr}}$ is the threshold ablation energy density.

The effect of overheating the target during its irradiation by an HPIB may be associated with metastable overheating (above the boiling point) of the molten subsurface layer of the target, when it is heated at a rate of above $3 \times 10^{10} \mathrm{~K} / \mathrm{s}$. The experimental data on the overheating of liquid metals obtained when heating a metal wire with a pulsed electric current at a heating rate of $10^{8}-10^{10} \mathrm{~K} / \mathrm{s}$ are given in [20]. The overheating (the ratio of the difference between the experimental boiling point of the metal and the equilibrium boiling temperature to the equilibrium boiling point of this metal) at the initial point of the explosion varied from $21 \%$ for $\mathrm{Al}$ to $114 \%$ for $\mathrm{Cd}$; it was $66 \%$ for copper and $110 \%$ for tungsten. The value of overheating did not change when the heating rate changed in the range of (280) $\times 10^{9} \mathrm{~K} / \mathrm{s}$.

In the process of pulsed laser heating of a metal target, which is similar to heating by a pulsed electric current, a thin subsurface metal layer was melted and overheated in the liquid state above its boiling point [21]. When the laser radiation density was high enough, overheating was accompanied by a transition to the metastable liquid phase. However, for a laser pulse duration that exceeded $5 \mathrm{~ns}$, the overheating did not exceed the critical temperature (the spinodal line of the phase diagram) [20], and the relative excess temperature did not exceed $66 \%$ for the copper target.

Overheating of most targets that are irradiated with an HPIB is significantly higher than overheating of metal wires subjected to pulsed heating with an elec- 

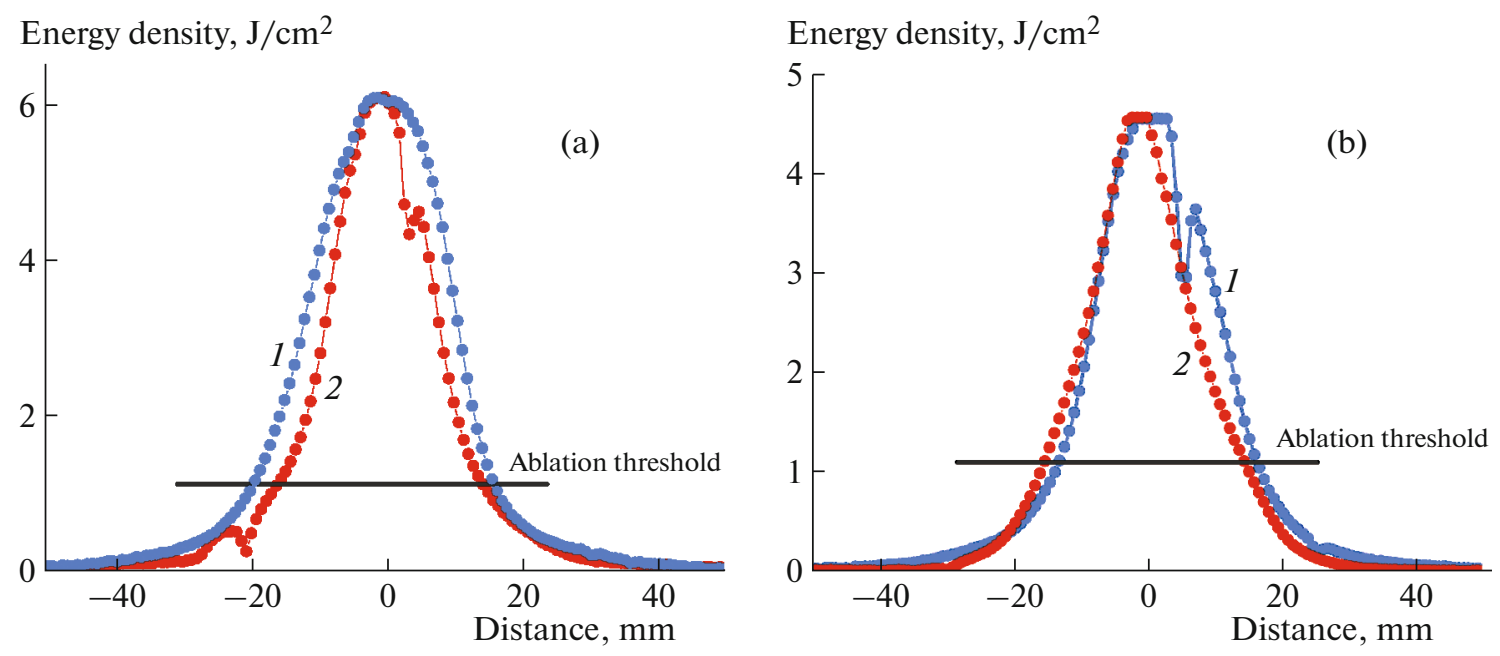

Fig. 5. The HPIB energy-density distribution at the focus in the (1) vertical and (2) horizontal directions for (a) brass and (b) titanium targets.

tric current or that of a pulsed-laser-heated metal target (see Table 1).

In addition, when a target is irradiated with an ion beam, its overheating depends on its size and thickness. When the thickness of a large brass target decreases its overheating increases from 220 to $435 \%$ [18]. Overheating of a small target reaches $350 \%$ and does not change when its thickness changes. When the HPIB pulse duration is shorter than 200 ns the thickness of the molten layer does not exceed $1 \mu \mathrm{m}$ [22] and an increase in the target thickness from 75 to $200 \mu \mathrm{m}$ must not affect the overheating process.

The target overheating under irradiation with an HPIB may be associated with the formation, migration, and subsequent annealing of radiation defects. When an ion beam irradiates a target, an elastic (nuclear) scattering mechanism with the formation of radiation defects is implemented [3]. Migration of radiation defects in metals has a small activation energy, which ensures their high mobility and annealing at temperatures of $100-200 \mathrm{~K}$ in stainless steel [23] and $120-130 \mathrm{~K}$ in titanium [24].
The temperature is very high in the subsurface layer of an HPIB-irradiated target, thus leading to a rapid migration of part of the defects from the ablation layer of the target and the subsequent energy release in the target during their annealing. The thickness of the target surface layer, which is evaporated under the HPIB irradiation, does not exceed $1 \mu \mathrm{m}$; thus, the migration of radiation defects does not take much time. Investigating the target cooling process after HPIB irradiation confirms the formation of a significant number of radiation defects [25].

The calibration dependence that was obtained from measurements of the HPIB energy density $[18,19]$ can be used to correct the results of TID of HPIBs under the conditions of intense ablation of the target material. To do this, it is necessary to measure the crosssectional distribution of the HPIB energy density, when the beam is attenuated by a metal grid (the total energy density) and without using a grid (the absorbed energy density) (Fig. 6). A stainless-steel mesh was installed at a distance of $10 \mathrm{~mm}$ in front of the target. When the focal length of the diode was $13 \mathrm{~cm}$, the HPIB energy density near the grid was significantly

Table 1. The HPIB energy density at the focus

\begin{tabular}{l|c|c|c|c}
\hline \multirow{2}{*}{$\begin{array}{c}\text { Material and } \\
\text { target thickness }\end{array}$} & $\begin{array}{c}\text { Threshold energy } \\
\text { density, } \mathrm{J} / \mathrm{cm}^{2}\end{array}$ & \multicolumn{2}{|c|}{ Energy density at the focus, $\mathrm{J} / \mathrm{cm}^{2}$} & \multirow{2}{*}{ Overheating, \% } \\
\cline { 3 - 4 } & 1.10 & $4.2-4.6$ & $4.8-5.1$ & $280-360$ \\
$\mathrm{Ti}, 50 \mu \mathrm{m}$ & 1.12 & $5.5-6.0$ & $4.5-5.0$ & $300-435$ \\
Brass, $75 \mu \mathrm{m}$ & 1.12 & $3.6-3.9$ & $4.4-5.0$ & $220-345$ \\
Brass, $200 \mu \mathrm{m}$ & 2.75 & $5.8-7.1$ & $6.5-7.0$ & $110-160$ \\
Stainless steel, $100 \mu \mathrm{m}$ & 4.80 & $5.5-5.8$ & $7.0-7.4$ & $15-55$ \\
$\mathrm{Cu}, 100 \mu \mathrm{m}$ & 5.54 & $5.4-5.6$ & - & $\approx 0$ \\
$\mathrm{~W}, 200 \mu \mathrm{m}$ & & & small target $\varnothing 10 \mathrm{~mm}$ & \\
\hline
\end{tabular}


(a)

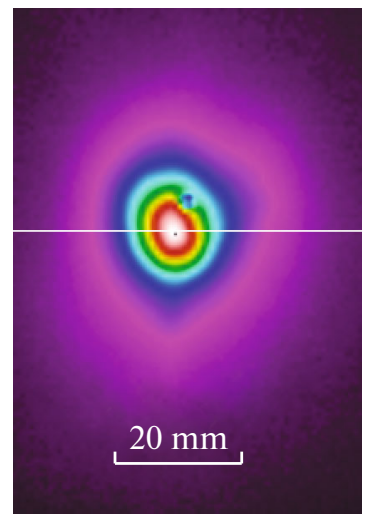

(b)

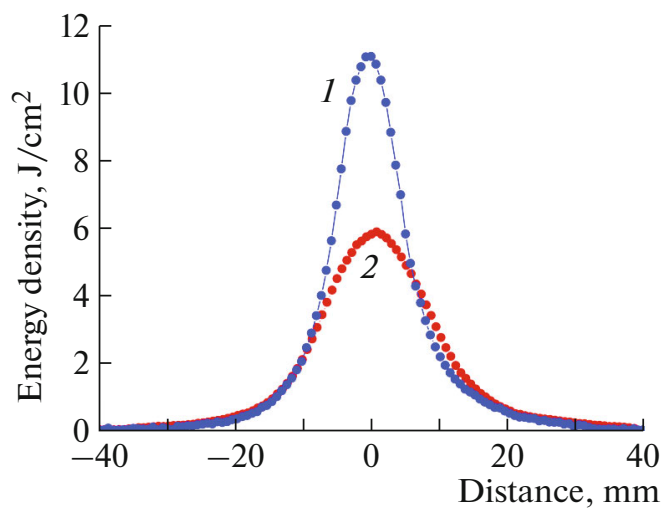

Fig. 6. (a) The HPIB IR image and (b) the energy-density distribution at the focus in the horizontal cross section: (1) when the HPIB is attenuated by a grid and using the calculation results; and (2) without a grid.
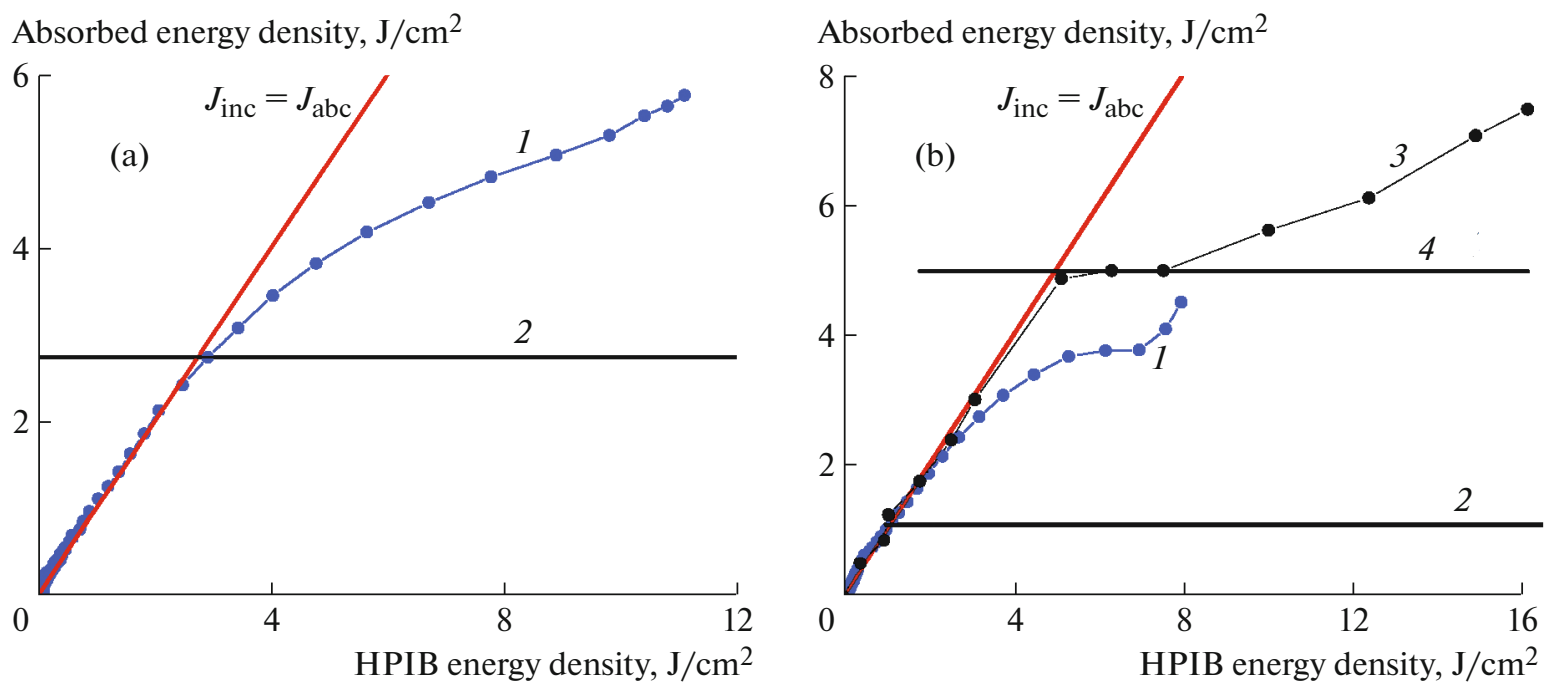

Fig. 7. $(1,3)$ The dependences of the absorbed-energy density and $(2,4)$ the threshold energy density on the total energy density for (a) stainless-steel and (b) titanium targets [18] and $(3,4)$ curves based on the results from [10].

lower than at the focus. This made it possible to eliminate the effect of reducing the optical transparency of the grid by ablation plasma. The energy density was calculated taking the optical transparency of the grid (50\%) into account. These results are shown in Fig. 7.

Similar results on the overheating of a 0.64 -mm-thick titanium target that was irradiated with a pulsed ion beam $(400 \mathrm{keV}, 30 \mathrm{kA}$, and a duration of $0.5 \mu \mathrm{s})$ were presented in [10] (Fig. 7b). The total energy density of the HPIB is equal to the integral of the product of the ion-current density and the accelerating voltage over the pulse duration. The use of the calibration curve extends the range of measuring the ion-beam energy density to $10-12 \mathrm{~J} / \mathrm{cm}^{2}$.

\subsection{The Effect of Radiation Defects on the Error of the Thermal-Imaging Diagnostics of HPIBs}

One of the mechanisms of the ion-energy absorption in metals is the elastic (nuclear) scattering by target atoms with the formation of primary radiation defects (Frenkel pairs) [26, 27]. These defects lead to changes in the mechanical properties of irradiated products [28], radiation swelling [29], etc. Studies have shown that the HPIB-formed radiation defects in the target significantly increase the maximum energy density that can be measured using TID due to their migration from the melting and ablation region, as well as their subsequent annihilation [30]. 
For TID, the total HPIB energy is calculated from the value of the thermal energy in the target immediately after the irradiation, since it is subsequently cooled via thermal radiation (see Fig. 2). However, a part of the HPIB energy that is spent on the formation of radiation defects does not participate in the target heating immediately after the irradiation, because the annihilation time of defects at a temperature of 100$200^{\circ} \mathrm{C}$ is tens of seconds [30]. This introduces a substantial error into the results of the HPIB energy-density measurements using TID. Table 2 presents the results of measuring the HPIB energy density when using targets made of different metals [31]. Each series of measurements consisted of ten consecutive pulses; the accelerator mode remained unchanged during studies of all targets. When targets made of different metals were used, TID readings differed by $40-60 \%$ with an energy-density instability in a series of pulses (for a single target) of at most $10 \%$.

A significant spread in TID readings with targets of different metals may be associated with different threshold ablation energies of these metals (the energy required for heating the surface layer of a target to the boiling point by a pulsed ion beam). When the effect of an HPIB with a duration of $150 \mathrm{~ns}$ was simulated it was obtained that the threshold ablation energy density is $1.1 \mathrm{~J} / \mathrm{cm}^{2}$ for a titanium target, $2.75 \mathrm{~J} / \mathrm{cm}^{2}$ for a stainless-steel target, and $4.8 \mathrm{~J} / \mathrm{cm}^{2}$ for a copper target [31] (see Table 1). Radiation defects that are formed in the target by the beam increase the threshold ablation energy density to $4.8-7.4 \mathrm{~J} / \mathrm{cm}^{2}$ due to the migration of defects from the ablation region and the subsequent annihilation [18]. In our experiments, the HPIB energy density did not exceed $4 \mathrm{~J} / \mathrm{cm}^{2}$; therefore, the ablation of the target material had no effect on TID readings when using targets of different metals.

The spread of TID readings when using targets made of different metals may also be due to different energy consumptions of the ion beam for the formation of radiation defects in these metals. Studies have shown that the energy loss of the HPIB for the formation of radiation defects $(5-10 \%$ higher than the annihilation energy of radiation defects during the target cooling) is proportional to the initial thermal energy in the target after its irradiation with the ion beam $[19,30]$. Therefore, the corrected (total) HPIB energy density $J_{\text {cor }}, \mathrm{J} / \mathrm{cm}^{2}$, can be calculated from the formula:

$$
J_{\text {cor }}=K_{1} K_{2} c_{V} d \rho \Delta T,
$$

where $K_{2}=1.22$ for a stainless-steel target, 1.3 for $\mathrm{Cu}$, and 1.7 for $\mathrm{Ti}$ [31].

Considering the HPIB energy loss for the formation of radiation defects makes it possible to eliminate the error in measuring the HPIB energy density (by 40-60\%) when using targets of different metals (see Table 2).
Table 2. The HPIB energy density at the focus

\begin{tabular}{l|c|c|c}
\hline \multirow{2}{*}{$\begin{array}{c}\text { Target } \\
\text { material }\end{array}$} & \multirow{2}{*}{$\begin{array}{c}\text { Measure- } \\
\text { ment series }\end{array}$} & \multicolumn{2}{c}{ Energy density, $\mathrm{J} / \mathrm{cm}^{2}$} \\
\cline { 3 - 4 } $\mathrm{Ti}$ & at the focus & corrected value \\
\hline \multirow{3}{*}{ Stainless steel } & Series 1 & $2.3 \pm 10 \%$ & $3.9 \pm 10 \%$ \\
& Series 2 & $2.3 \pm 9 \%$ & $3.9 \pm 9 \%$ \\
$\mathrm{Cu}$ & Series 1 & $3.2 \pm 6 \%$ & $3.9 \pm 6 \%$ \\
& Series 2 & $3.3 \pm 6 \%$ & $4.0 \pm 6 \%$ \\
& Series 1 & $3.6 \pm 6 \%$ & $4.6 \pm 6 \%$ \\
\hline
\end{tabular}

\section{THE TIME-OF-FLIGHT DIAGNOSTICS OF ION BEAMS}

The HPIB composition determines the depth of the modified layer of a processed product and the absorbed-dose value. Therefore, when optimizing the product processing mode, it is important to control the ion composition and ratio of the ion concentrations in the beam. In metals and alloys, the range in the target for ion energies of 200-300 keV does not exceed $0.5-1 \mu \mathrm{m}$; however, for a pulse duration of $0.2 \mu \mathrm{s}$, the heat front propagates to a depth of $2 \mu \mathrm{m}$ by the end of the pulse [32, 33]. Therefore, for metal products, the HPIB composition is not so important as the propagation depth of the heat front. However, in order to study the operation of an ion diode and calculate the increase in the ion-current density compared to the calculated value according to the Child-Langmuir equation [34] it is important to know the composition of the formed ion beam.

A method for studying the ion-beam composition by their spatial separation using a magnetic field was first proposed by J.J. Thomson in 1913 (Thomson spectrometer). In 1919, E.W. Aston developed a prototype of a modern magnetostatic mass spectrometer [35]. The separation of ions with large masses in a Thomson spectrometer requires the use of a magnetic field with an induction that exceeds $1 \mathrm{~T}$, thus increasing the size and mass of the instrument.

In a Thomson spectrometer, detailed information on the beam composition and ion-energy distribution is obtained using the track diagnostics in CR-39 plastics $[36,37]$. However, processing the registrating plates takes a long time. Correct information can be obtained only when studying the beam composition in a single pulse, which makes it difficult to monitor changes in the HPIB composition in a series of pulses. The use of photosensitive semiconductor arrays in a Thompson spectrometer [38] is hampered due to the destruction of photosensitive elements in high-voltage HPIB sources.

The HPIB composition can be analyzed using the spatial separation of different ions along their drift path from the diode to the registering device. The first time-of-flight (TOF) analyzer was constructed by Wiley, MacLaren in 1955 [39]. A more detailed over-

Vol. 63 No. $3 \quad 2020$ 

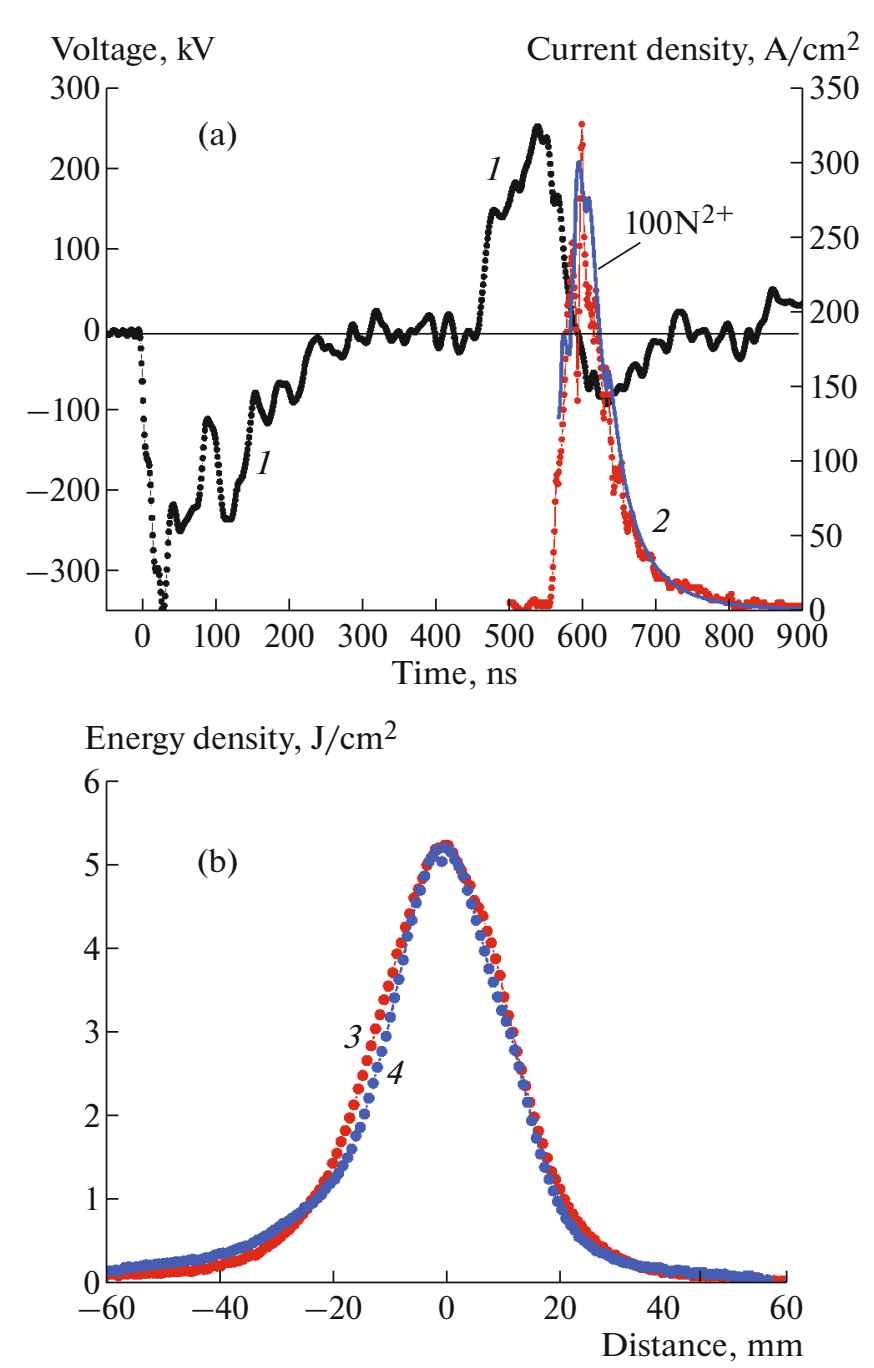

Fig. 8. (a) Waveforms of the (1) accelerating voltage and (2) the experimental (dots) and ion-current density calculated according to the TOF diagnostics (line); and (b) the HPIB energy-density distribution at the focus in the (3) vertical and (4) horizontal directions.

view of the history of the development of TOF mass spectrometers from the time of their invention up to now was presented in [40]. The use of a high-speed Faraday cup and a broadband oscilloscope allows one to quickly monitor the HPIB composition using a sensor that is installed at a distance of $10-15 \mathrm{~cm}$ from the diode. The TOF diagnostics of an HPIB provides rapid monitoring of changes in the beam composition in a series of pulses.

When accelerated in the anode-cathode gap of a diode, ions with different masses and degrees of ionization acquire the same energy but different velocities $[41,42]$. In this case, it is believed that ions of different types are formed in the diode synchronously during a pulse of the accelerating voltage and that their speed does not change on the drift path. For an HPIB energy density below $10 \mathrm{~J} / \mathrm{cm}^{2}$ and a pulse duration of $150 \mathrm{~ns}$, the ion concentration is at most $10^{13} \mathrm{~cm}^{-3}$; therefore, the probability of their collisions (and velocity changes) in the drift region is low. The divergence of ions in the HPIB is $5^{\circ}-8^{\circ}[43]$.

For each instant of time of the HPIB generation, the accelerating voltage (with a step of $1 \mathrm{~ns}$ ) is used to calculate the current density for ions of a particular type and the delay time of arrival of these ions at the collimated Faraday cup (CFC). The calculated curves are compared with the experimental data [7, 12]. This method allows determination of the HPIB composition more precisely than when using the delay of the maximum amplitude of the ion-current density relative to the maximum accelerating-voltage amplitude [44-46]. Figure 8 shows typical waveforms of the accelerating voltage and the density of the ion current that is generated by the focusing diode when operating in the two-pulse mode [6]. The distance to the CFC is $14 \mathrm{~cm}$.

The results of measuring the HPIB energy density confirm the correctness of the TOF diagnostics. The energy density $q, \mathrm{~J} / \mathrm{cm}^{2}$, is equal to the integral of the product of the accelerating voltage and the ion-current density calculated from the one-dimensional ChildLangmuir equation:

$$
\begin{gathered}
q_{\mathrm{cal}}(t)=\int_{t_{0}}^{\infty} U(t) j(t) d t \\
=\frac{4 K_{3} \varepsilon_{0} \sqrt{2 z}}{9 \sqrt{m_{\mathrm{i}}}} \int_{t_{0}}^{\infty} \frac{U^{5 / 2}(t) d t}{\left[d_{0}-v\left(t-t_{0}\right)\right]^{2}}
\end{gathered}
$$

where $z$ is the ion charge, $m_{\mathrm{i}}$ is the ion mass, $d_{0}$ is the initial anode-cathode gap, $\varepsilon_{0}$ is the absolute permittivity, $U$ is the accelerating voltage, $V$ is the plasma expansion speed, $K_{3}$ is the gain of the ion-current density, and $t_{0}$ is the time when the polarity at the anode changes $\left(t_{0}=450 \mathrm{~ns}\right.$ in Fig. 8a).

For the experimental data in Fig. 8a, the HPIB energy density, which is calculated from the results of the TOF diagnostics (for $\mathrm{N}^{2+}$ ions), is $4.3 \mathrm{~J} / \mathrm{cm}^{2}$, which is $20 \%$ lower than that according to TID results (see Fig. 8b). The discrepancy is related to the use of TID to register the target heating by ions and accelerated atoms, which are produced during the ion charge exchange [6, 47].

The TOF diagnostics of pulsed ion beams that contain light (protons or deuterons) and heavy $\left(\mathrm{C}^{+}\right.$or $\mathrm{N}^{+}$, $\mathrm{Cu}^{+}, \mathrm{Fe}^{+}$) ions showed a delay in registering light ions by the Faraday cup in comparison with the calculated values [48]. The delay of protons with energies of 250$300 \mathrm{keV}$ was $40-50 \mathrm{~ns}$ on a drift path of $14-16 \mathrm{~cm}$. With a deuteron energy of $1 \mathrm{MeV}$ on a drift path of $45 \mathrm{~cm}$, the delay was $16 \mathrm{~ns}$ [49]. At a low proton concentration, the ion-registration delay did not exceed the TOF diagnostic error. The delay in registering light ions is due to their deceleration by the space charge of 


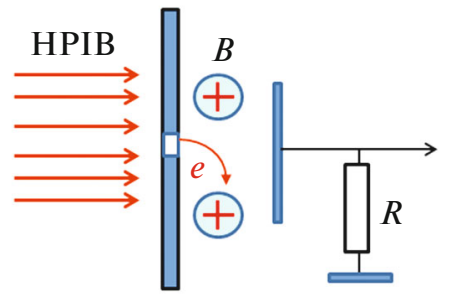

Fig. 9. A diagram of electron motion in the CFC with magnetic cutoff.

the HPIB (which is negative due to an excess concentration of low-energy electrons) in the drift region from the diode to the CFC [48].

When analyzing the HPIB composition a Faraday cup is used as an ion-registering device, which mainly determines the accuracy of the TOF diagnostics and its resolution. In order to efficiently transport and focus an HPIB it is necessary to provide its charge neutralization by electrons. Otherwise, it will crumble as a result of Coulomb repulsion. However, when measuring the ion-current density using a Faraday cup it is necessary to remove electrons from the HPIB. A transverse magnetic field (a CFC with a magnetic cutoff) or an electric field (a CFC with electric biasing) is used for this purpose.

The CFC is designed to measure the ion-current density. It is a charge collector connected to a resistor. The studied particle beam is incident on the collector through a collimating hole of a certain diameter. Lowenergy electrons that compensate for the charge of the beam ions are deflected under the action of a Lorentz force in a magnetic field and do not land on the CFC collector (Fig. 9). The radius of motion of electrons in the magnetic field (Larmor radius) is:

$$
R_{\mathrm{L}}=\frac{m v}{e B}=\frac{\sqrt{2 m E}}{e B},
$$

where $E$ is the electron kinetic energy.

Figure 10 shows the dependence of the Larmor radius on the electron energy. The energy of the electrons that compensate for the charge of ions in the HPIB does not exceed $10 \mathrm{keV}$; the magnetic field that is created by permanent magnets $(0.2-0.3 \mathrm{~T})$ prevents electrons from arriving at the collector even at small CFC dimensions.

A powerful ion beam, in which the charge of ions is compensated by electrons, consists of plasma that suppresses the penetration of the magnetic field into its volume. When the frequency of electromagnetic radiation is considerably lower than the frequency of Langmuir oscillations, the magnetic field penetrates into plasma to the skin depth defined as [50]

$$
\lambda_{e}=\frac{c}{\sqrt{\omega_{p}^{2}-\omega^{2}}} \approx \frac{c}{\omega_{p}},
$$

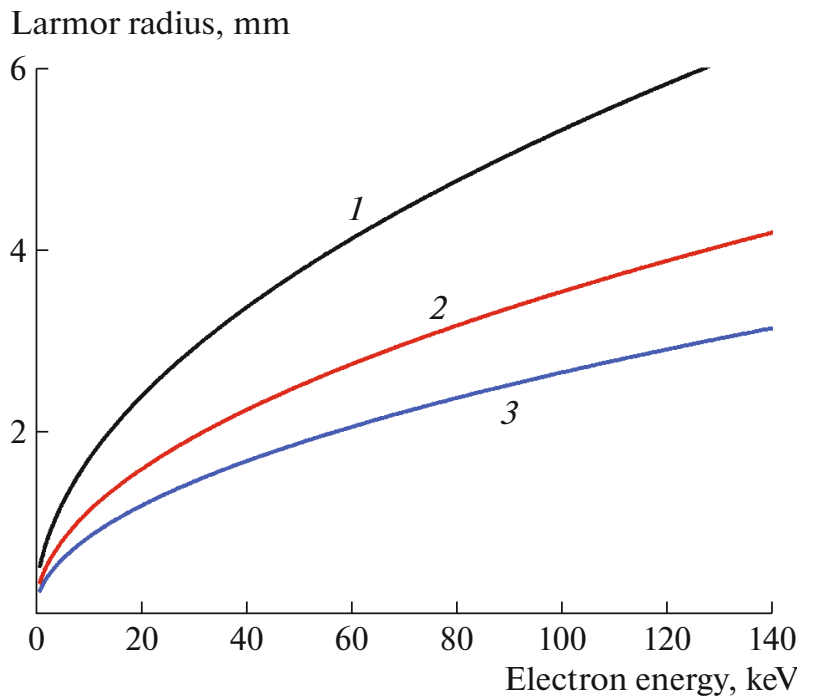

Fig. 10. The dependences of the Larmor radius on the electron energy at magnetic inductions of (1) 0.2 , (2) 0.3 , and (3) $0.4 \mathrm{~T}$.

where $c$ is the velocity of light and $\omega_{p}$ is the Langmuir oscillation frequency.

The numerical value of the Langmuir frequency can be determined from the relationship $\omega_{p}=5.64 \times$ $10^{4} n_{e}^{0.5} \mathrm{~Hz}$, where $n_{e}, \mathrm{~cm}^{-3}$ is the electron concentration. In this case, the skin depth (the distance at which the magnetic-field induction decreases by 2.7 times) is:

$$
\lambda_{e}[\mathrm{~cm}]=\frac{5.3 \times 10^{5}}{\sqrt{n_{e}}} .
$$

For a HPIB with singly ionized ions at the complete charge neutralization, $n_{e}=n_{i}$. The ion concentration in the HPIB can be calculated from the formula [6]:

$$
n_{i}(t)=\frac{j_{i}(t)}{z v_{i}}=\frac{j_{i}(t) \sqrt{m_{i}}}{z \sqrt{2 z U(t)}}
$$

where $j_{i}$ is the ion-current density and $v_{i}$ is the ion velocity in the drift region $\left(v_{i}=\right.$ const $)$.

Figure 11 shows the results of calculating the thickness of the skin layer depending on the ion-current density. The value of the skin layer in an ion beam with a current density of $200-300 \mathrm{~A} / \mathrm{cm}^{2}$ is $2-4 \mathrm{~mm}$. Therefore, to provide effective electron removal, the diameter of the collimating hole in the CFC with magnetic cutoff can be 4-8 mm.

The energy spectrum of ions is one of the most important characteristics of an HPIB, which determines its depth distribution when absorbed in a target. The TOF diagnostics allows one to quickly monitor the spectrum separately for each type of ion. In this case, for each value of the accelerating voltage that is registered with a digital oscilloscope (at a step of $1 \mathrm{~ns}$ ), the time delay is calculated and a curve of the change 


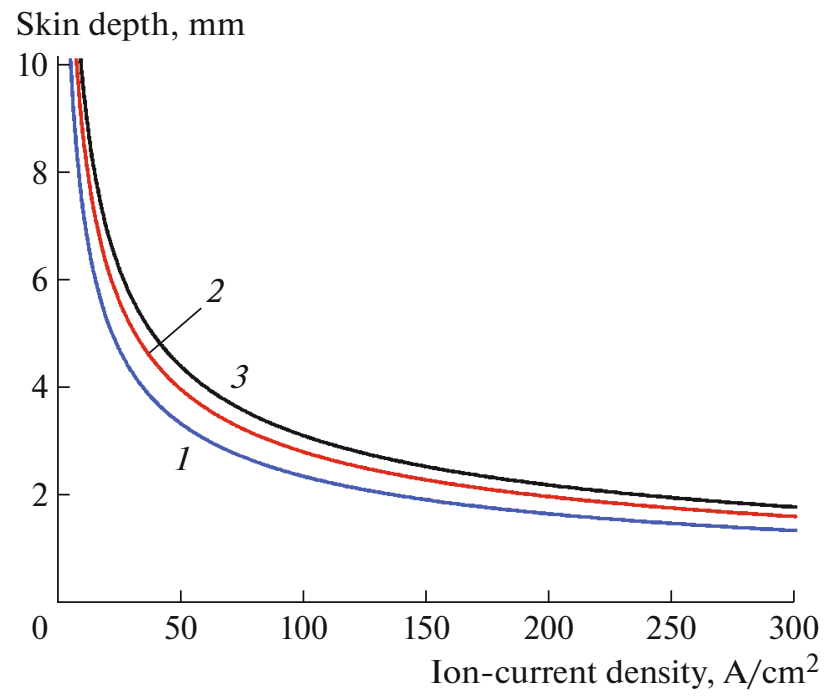

Fig. 11. The dependences of the HPIB skin depth on the ion-current density at ion energies of (1) 100 , (2) 200 , and (3) $300 \mathrm{keV}$.

in the kinetic energy of a certain type of ions is constructed, which is synchronous with the CFC signal waveform [12]. The energy spectra of ions that are formed by a flat diode with a graphite anode are shown in Fig. 12.

The TOF diagnostics allows one to determine the main characteristics of the HPIB: the beam composition and the absolute values of the total fluence of ions, the fluence of ions of different masses, and degrees of ionization, as well as the energy spectrum of each type of ion. Monitoring the parameters of an HPIB does not require complex equipment and longterm processing of the measurement results. The diagnostics was successfully tested on different ion accelerators that form HPIBs with complex compositions with powers of 6-8 GW and concentrations of up to $10^{13} \mathrm{~cm}^{-3}$.

\section{THE DIAGNOSTICS OF ELECTRON BEAMS}

The widespread use of pulsed electron beams for pumping gas lasers, initiating nonequilibrium plasmachemical processes, etc., requires the formation of large-area electron beams with highly uniform crosssectional energy densities [51]. A sectioned calorimeter is used to measure the beam energy distribution in the cross section [52]. However, to provide a spatial resolution better than $1 \mathrm{~mm}$ for a beam area that exceeds $20 \mathrm{~cm}^{2}$, the calorimeter design becomes complex and the measurement process takes a long time. A sectioned calorimeter designed for registering an electron beam was described in [53]. The collector of the calorimeter, with a diameter of $100 \mathrm{~mm}$, has 61 sections,

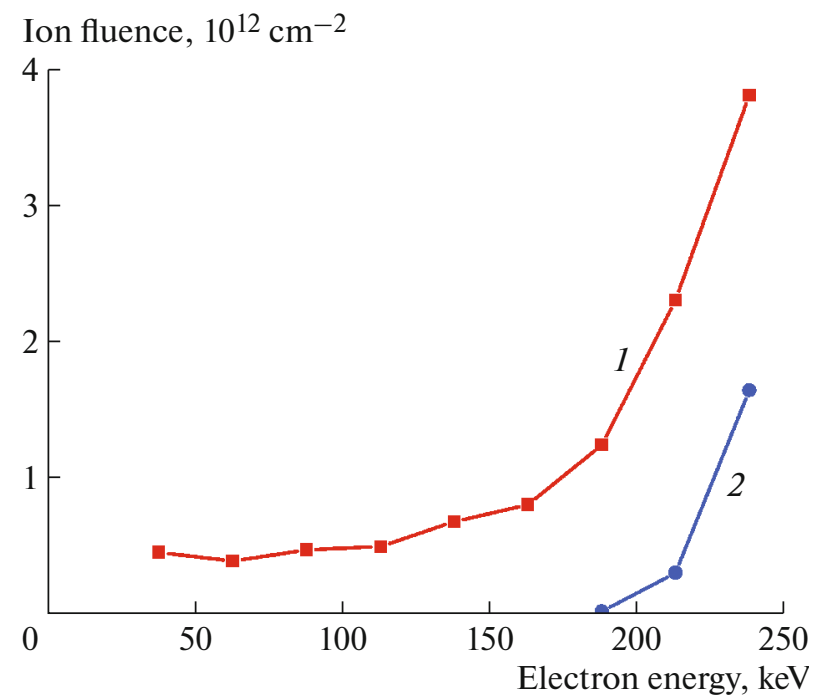

Fig. 12. The spectra of the fluences of (1) $\mathrm{C}^{+}$ions and (2) protons generated by a flat diode.

whose temperature was determined using a thermal imager.

Luminescence of natural minerals can be used to analyze the cross-sectional structure of a pulsed electron beam $[54,55]$. A long afterglow time (>10 min) allows registration of the electron-beam profile. However, this method cannot be used to measure the absolute values of the electron current density or energy density. In addition, when a mineral is repeatedly irradiated with an electron beam its properties change due to the formation of radiation defects, which introduce an error into the measurement results.

A dosimetric radiation-sensitive film (a copolymer with a phenazine dye) of the POR type has been used to measure the absorbed dose under the irradiation with an electron beam [56, 57]. The value of the absorbed dose is calculated by changing the optical density of the dosimetric film at a wavelength of $512 \mathrm{~nm}$ according to the calibration dependence attached by the film manufacturer. The film thickness is $0.1 \mathrm{~mm}$ (the thickness of the sensitive layer is $15 \mu \mathrm{m}$ ), which allows recording the absorbed dose with high spatial resolution.

To calculate the cross-sectional energy-density distribution of an electron beam, it is necessary to measure the optical-density distribution $(\lambda=512 \mathrm{~nm})$ of a beam impression on a dosimetric film over a large area with a high spatial resolution. Using a spectrophotometer allows one to operate in the region of a linear dependence of the optical density on the absorbed dose but significantly complicates the measurement procedure. When the diameter of the spectrophotometer probe beam becomes smaller than $5 \mathrm{~mm}$ the error of measuring the optical density in the region of large absorbed doses increases. 
Correlations of the optical density $(\lambda=512 \mathrm{~nm})$ of the dosimetric film and the "light" parameter of the digital image of the film were investigated to simplify the procedure of processing a dosimetric film with an imprint of a pulsed electron beam [6]. The "light" parameter was extracted from the digital image of the film using the MathCad $2001^{\mathrm{TM}}$ math package by a function built into the package. The dosimetric film was scanned on an HP Scanjet $3970^{\mathrm{TM}}$ scanner using the slide scanning mode with a hardware spatial color resolution of $200 \mathrm{dpi}$ RGB. The "light" parameter provided a good correlation with the optical density of the film that was measured with the spectrophotometer $(\lambda=512 \mathrm{~nm})$; the dependence of the absorbed dose $D$, kGy, on the "light" parameter $L$, rel. units, was described by the formula $D=368-4.59 L+0.014 L^{2}$ with an error of $1.2 \%$.

The impression of a pulsed electron beam on a dosimetric film was processed in the following order:

- scanning the film on a scanner with high color and coordinate resolutions;

- composing a two-dimensional matrix of the "light" parameter from a digital image;

- processing a "light"-parameter matrix in the ORIGIN 9.1 OriginLab Corporation program [58] and composing an absorbed-dose matrix;

- converting the absorbed-dose matrix to an electron-beam energy density matrix in the ORIGIN 9.1 program;

- representing the electron-beam energy density matrix as a three-dimensional graph.

Figure 13 shows a two-dimensional distribution of the energy density of a pulsed electron beam (one pulse) that was obtained using the above algorithm. The anode foil of the accelerator lies on a support grid with 5-mm-wide slots.

Studies have shown that dosimetric film allows measurements of the energy-density distribution of a pulsed electron beam with a resolution of $1 \mathrm{~mm}$ and an energy density in the range of $0.1-10 \mathrm{~J} / \mathrm{cm}^{2}$. However, the high cost of the film limits its use. In addition, after dosimetric film is irradiated, it must be held for 5-6 h to stabilize radiation-chemical processes [56]. Dosimetric film is designed to register the absorbed dose at an electron energy that exceeds $300 \mathrm{keV}$ [56], thus also limiting its application, especially for pulsed electron beams with a wide energy spectrum.

TID is used for on-line monitoring of the parameters of a high-current electron beam [59-62]. It provides measurements of the cross-sectional electronbeam energy density distribution, the total energy of the electron beam, and the electron-energy spectrum. The diagnostics is based on measuring the thermal imprint of an electron beam on a metal target $[61,62]$ or in a material with a low bulk density and a low thermal conductivity $[6,59]$. In contrast to the technique using radiosensitive (dosimetric) materials, TID requires

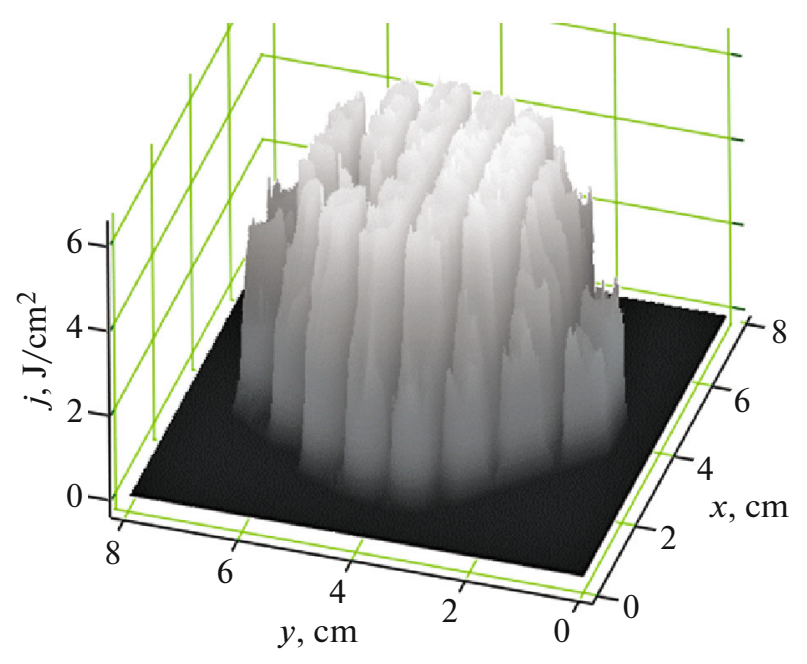

Fig. 13. A 2D image of the cross-sectional distribution of the pulsed electron-beam energy.

neither expensive consumables nor a large amount of time for processing.

The cross-sectional energy-density distribution of a pulsed electron beam is measured using the thermal imprint of the beam on a metal target. The measurement scheme and the calculation formulas are similar to TID of high-power ion beams [61, 62].

The distribution of the absorbed dose in the target depth depends on the electron spectrum in the beam; thus, TID can be used for rapid monitoring of the electron energy spectrum. A cut was preliminarily made along the diameter of a polystyrene-foam cylindrical target in order to measure the absorbed-dose distribution of the electron beam over the target depth. After irradiating the target with a pulsed electron beam the cut target was opened and a thermal image was recorded on its inner surface.

Figure 14 shows waveforms of the accelerating voltage generated by the TEU-500 accelerator [63] and an IR image of the inner target surface. The target diameter is $85 \mathrm{~mm}$ and its thickness is $110 \mathrm{~mm}$. The electron movement direction is upwards. The IR images were processed using the SmartView 4.1 program (Fluke Corporation) [64]. Figure 15 shows the absorbed-dose distribution over the target depth and the results of simulation the absorption of a monoenergetic electron beam in polystyrene-foam with a density of $0.016 \mathrm{~g} / \mathrm{cm}^{3}$ according to the PCLab program [65]. As can be seen from Figs. 14 and 15, when the accelerating voltage increases from 300 to $380 \mathrm{kV}$ (Fig. 14a), the extrapolated electron path increases from 60 to $85 \mathrm{~mm}$ (Fig. 15).

TID allows rapid monitoring of the most important parameters of pulsed electron beams: the cross-sectional energy-density distribution; the electron energy spectrum; and the total beam energy per pulse. The time for recording IR image does not exceed $0.1-0.2 \mathrm{~s}$. If a correct mode of irradiation of the polystyrene 


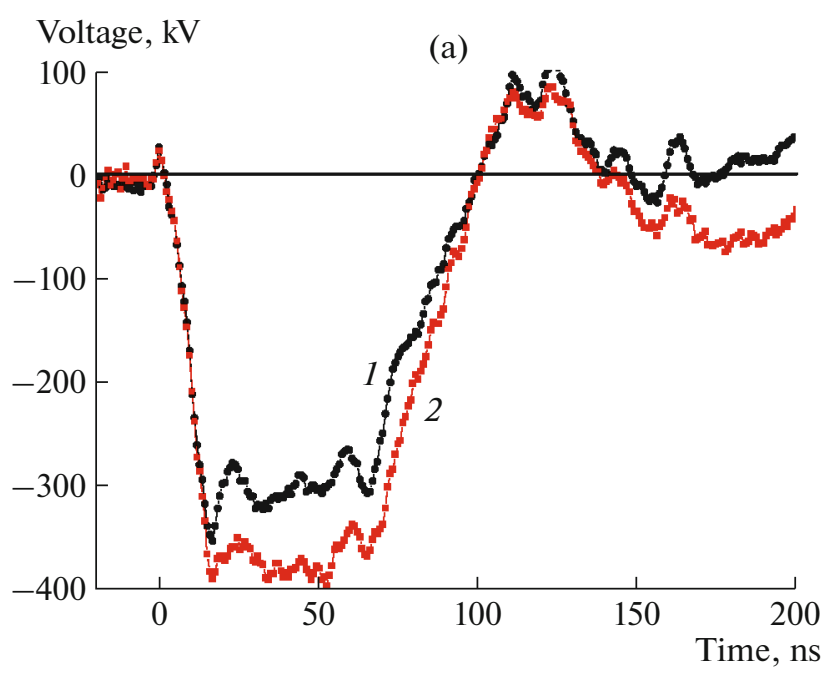

(b)

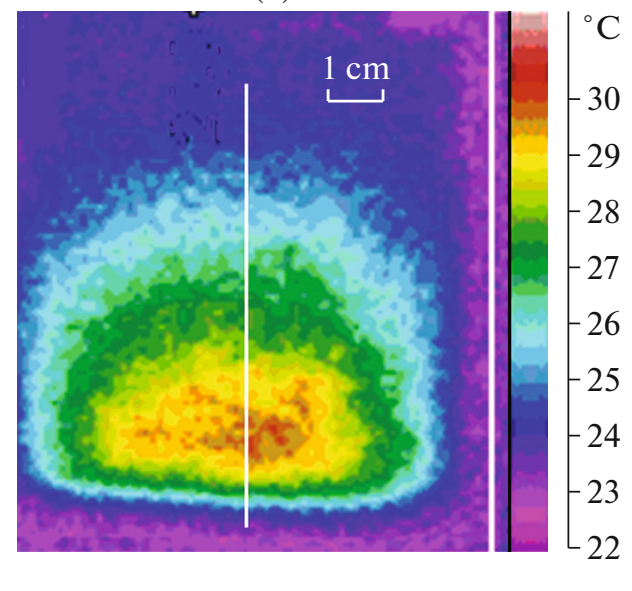

Fig. 14. (a) Waveforms of the accelerating voltage at an anode-cathode gap of (1) 10.5 and (2) 16 mm; and (b) an IR image of the target at an anode-cathode gap of $16 \mathrm{~mm}$.

foam target is selected it does not melt, thus providing a long operation life.

The performed tests of the developed TID have shown that the sensitivity of a typical thermal imager provides registration of the thermal imprint of a pulsed electron beam in a single pulse at a low energy density. When registering a pulsed electron beam with an electron energy of 350-400 keV, the minimum energy density that can be registered by TID does not exceed $0.1 \mathrm{~J} / \mathrm{cm}^{2}$ or $10 \mathrm{~A} / \mathrm{cm}^{2}$ at a pulse duration of $60 \mathrm{~ns}$. The target is cooled slowly and the temperature decreases by $5-7 \%$ within the first $3 \mathrm{~s}$. The slow target cooling

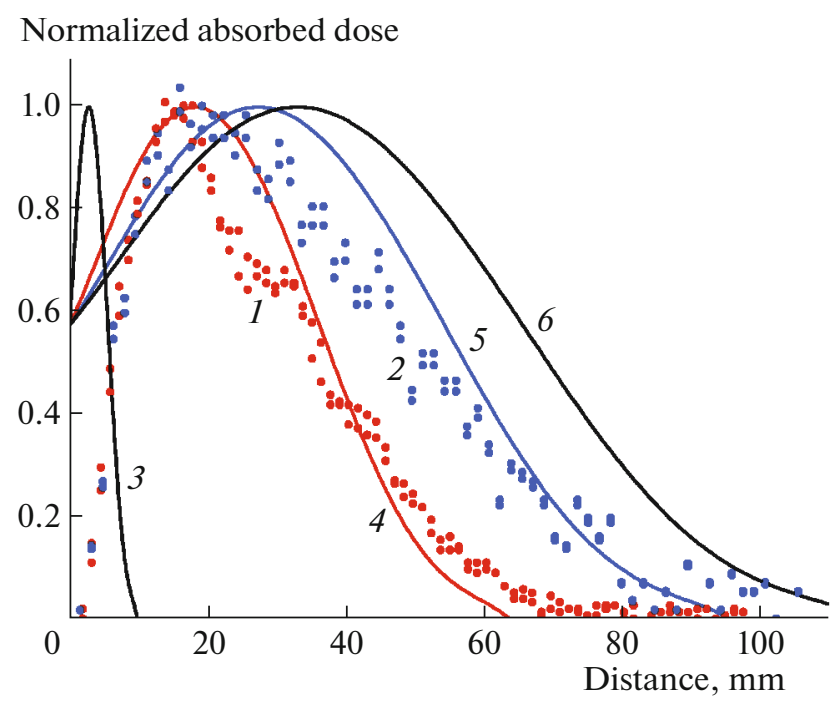

Fig. 15. The normalized absorbed-dose distribution in the target depth (dots) at an anode-cathode gap of (1) 10.5 and (2) $16 \mathrm{~mm}$. The results of simulating the absorption of electrons (lines) with energies of (3) 100, (4) 300, (5) 380, and (6) $500 \mathrm{keV}$. makes it possible to increase the sensitivity of TID by registering the thermal imprint of several beam pulses. At 140 pixels in the matrix of the Fluke Ti10 thermal imager, the spatial resolution is $0.9 \mathrm{~mm}$.

\section{CONCLUSIONS}

The analytical review and testing results of various methods for studying pulsed beams of electrons, ions, and accelerated atoms that are intended for technological applications have shown that thermal imaging diagnostics provides the most complete and reliable information.

An HPIB has a wide range of ion energy and a complex elemental composition. Measurements of the HPIB energy density make it possible to determine the integral (during the pulse duration) thermal effect of all ions regardless of their kinetic energy and degree of ionization. The monitoring of the HPIB that contains a significant fraction of accelerated atoms only by the amplitude of the ion-current density pulse does not allow for taking the thermal effect of neutrals into account. Measurements of the HPIB energy density make it possible to determine the total effect of ions and accelerated atoms and eliminate the systematic error associated with uncontrolled changes in the accelerating voltage when changing the ion-diode operation mode.

Monitoring the amplitude of the ion-current density pulse provides measurements in the local region, whose area does not exceed $0.5 \%$ of the entire beam area. The total ion current is subsequently calculated from the empirical correlation that takes the cross-sectional distribution of the ion current density into account. This approach introduces a significant error not only into the diagnostics of the HPIB impact on a workpiece but also into the calculation of the diode operation efficiency. The use of TID allows determination of the full infor- 
mation about the HPIB energy distribution over the beam cross section in a single pulse.

Due to the influence of the energy-density stabilization mechanism [6], analysis of the stability of the HPIB thermal effects on a target based on the amplitude of the ion-current density pulse gives an overestimated value of the standard deviation. In addition, the ion current generation is not synchronous across the beam cross section, and local monitoring of the ion current density does not provide reliable information on the processing of the entire product. In contrast to the amplitude of the ion-current density pulse, the correlation of the total beam energy and the energy density at the diode focus from the full charge is $0.85-$ 0.93 [76], thus allowing monitoring of the irradiation mode of the entire product without direct measurements of the HPIB parameters.

The effect of shifting the region of the maximum ionbeam energy density in the focal plane relative to the region of the maximum ion current density [77] additionally confirms that monitoring the effect of a pulsed ion beam of gigawatt power on the target by the density energy provides more correct and complete information than the ion-current density measurements.

TID allows one to determine the cross-sectional distribution of the ion-beam energy density with a high spatial resolution. The thermogram measurement time does not exceed $0.1 \mathrm{~s}$; however, the long target-cooling time after the ion-beam irradiation does not allow control of the ion-beam parameters at a high pulse repetition rate. To measure the cross-sectional distribution of the HPIB energy density at a high pulse repetition rate, acoustic (thermal-radiation) diagnostics should be used. Acoustic diagnostics allows measurement of the beam energy density in the range of $0.1-2 \mathrm{~J} / \mathrm{cm}^{2}$. When the energy density exceeds $2 \mathrm{~J} / \mathrm{cm}^{2}$, the signal amplitude from the piezosensor is stabilized due to melting of the surface layer of the target.

\section{ACKNOWLEDGMENTS}

This study was supported by the Russian Foundation for Basic Research, project no. 19-38-90001.

\section{SUPPLEMENTARY MATERIALS}

Supplementary materials are available for this article at https://doi.org/10.1134/S0020441220030148 and are accessible for authorized users.

\section{OPEN ACCESS}

This article is distributed under the terms of the Creative Commons Attribution 4.0 International License (http:// creativecommons.org/licenses/by/4.0/), which permits unrestricted use, distribution, and reproduction in any medium, provided you give appropriate credit to the origi- nal author(s) and the source, provide a link to the Creative Commons license, and indicate if changes were made.

\section{REFERENCES}

1. Bystritskii,V.M. and A.N. DidenkoA.N., High-power ion beams. American Institute of Physics, New York, 1989.

2. Boiko, V.I., Skvortsov, V.A., Fortov, V.E., and Shamanin, I.V., Vzaimodeistvie impul'snykh puchkov zaryazhennykh chastits s veshchestvom (Interaction between Pulse Charged-Particle Beams and Matter), Moscow: Fizmatlit, 2003.

3. Was, G.S. and Averback, R.S., Radiation Damage Using Ion Beams, in Comprehensive Nuclear Materials, Elsevier, 2012, vol. 1.

4. Zinkle, S.J. and Snead, L.L., Scr. Mater., 2018, vol. 143, p. 154.

https://doi.org/10.1016/j.scriptamat.2017.06.041

5. Was, G.S., J. Mater. Res., 2015, vol. 30, p. 1158. https://doi.org/10.1557/jmr.2015.73

6. Pushkarev, A.I., Isakova, Yu.I., Sazonov, R.V., and Kholodnaya, G.E., Generatsiya puchkov zaryazhennykh chastits $v$ diodakh so vzryvoemissionnym katodom (Generation of Charged Particles Beams in Diodes with Explosive Emission Cathodes), Moscow: Fizmatlit, 2013.

7. Isakova, Y.I. and Pushkarev, A.I., Instrum. Exp. Tech., 2013, vol. 56, no 2, pp. 185-192. https://doi.org/10.1134/S0020441213020085

8. Pushkarev, A.I., Isakova, Y.I., and Khaylov, I.P., Instrum. Exp. Tech., 2015, vol. 58, no. 5, p. 667. https://doi.org/10.1134/S0020441215040090

9. Christodoulides, C.E. and Freeman, J.H., Nucl. Instrum. Methods, 1976, vol. 135, no. 1, p. 13. https://doi.org/10.1016/0029-554X(76)90819-3

10. Davis, H.A., Bartsch, R.R., Olson, J.C., Rej, D.J., and Waganaar, W.J., J. Appl. Phys., 1997, vol. 82, p. 3223. https://doi.org/10.1063/1.365629

11. Xiao Yu, Jie Shen, Miao Qu, Wenbin Liu, Haowen Zhong, Jie Zhang, Yanyan Zhang, Sha Yan, Gaolong Zhang, Xiaofu Zhang, and Xiaoyun Le, Vacuum, 2015, vol. 113, p. 36. https://doi.org/10.1016/j.vacuum.2014.12.003

12. Pushkarev, A.I. and Isakova, Yu.I., Diagnostika moshchnykh ionnykh puchkov (Diagnostics of Powerful Ion Beams), Novosibirsk: SibAK, 2016.

13. Parker, W.J., Jenkins, R.J., Butler, C.P., and Abbott, G.L., J. Appl. Phys., 1961, vol. 32, p. 1679. https://doi.org/10.1063/1.1728417

14. Filippov, L.P., Izmerenie teplofizicheskikh svoistv veshchestv metodom periodicheskogo nagreva (Measurement of Thermophysical Properties of Substances by means of Periodical Heating Method), Moscow: Energoatomizdat, 1984.

15. Xiao Yu, Jie Shen, Miao Qu, Haowen Zhong, Jie Zhang, Yanyan Zhang, Sha Yan, Gaolong Zhang, Xiaofu Zhang, and Xiaoyun Le, Nucl. Instrum. Methods Phys. Res., Sect. B, 2015, vol. 365, p. 225.

https://doi.org/10.1016/j.nimb.2015.07.061 
16. Renk, T.J., Harper-Slaboszewicz, V., Mikkelson, K.A., Ginn, W.C., Ottinger, P.F., and Schumer, J.W., Phys. Plasmas, 2014, vol. 21, p. 123114. https://doi.org/10.1063/1.4903947

17. Zhu, X.P., Ding, L., Zhang, Q., Isakova, Yu., Prima, A., Pushkarev, A., and Lei, M.K., Laser Part. Beams, 2018, vol. 36, p. 470 .

https://doi.org/10.1017/S0263034618000514

18. Pushkarev, A., Zhu, X.P., Prima, A., Egorova, Yu., and Lei, M.K., Laser Part. Beams, 2019, vol. 37, p. 260. https://doi.org/10.1017/S0263034619000466

19. Pushkarev, A.I., Egorova, Yu.I., Prima, A.I., Korusenko, P.M., and Nesov, S.N., Generatsiya, diagnostika $i$ primenenie moshchnykh ionnykh puchkov s vysokoi plotnost'yu energii (Generation, Diagnostics, and Application of Powerful Ion Beams with a High Energy Density), Novosibirsk: SibAK, 2019.

20. Martynyuk, M.M., Fazovye perekhody pri impul'snom nagreve (Phase Transitions under Pulse Heating), Moscow: People's Friendship University of Russia, 1999.

21. Upadhyay, A.K., Inogamov, N.A., Rethfeld, B., and Urbassek, H.M., Phys. Rev. B, 2008 , vol. 78, p. 045437. https://doi.org/10.1103/PhysRevB.78.045437

22. Yu, X., Shen, J., Qu, M., Liu, W., Zhong, H., Zhang, J., Yan, S., Zhang, G., and Le, X., Rev. Sci. Instrum., 2015, vol. 86, p. 83305 .

https://doi.org/10.1063/1.4928069

23. Wolfer, W.G., Fundamental Properties of Defects in Metals, in Comprehensive Nuclear Materials, Amsterdam: Elsevier, 2012, vol. 1.

24. Jung, P., Atomic Defects in Metals, Berlin, Heidelberg: Springer, 1991.

25. Pushkarev, A., Prima, A., Zhu, X.P., Ding, L., Zhang, Q., Isakova, Yu., and Lei, M.K., Proc. 6th Int. Congress on Energy Fluxes and Radiation Effects (EFRE 2018), Tomsk: Siberian Branch Russ. Acad. Sci., 2018, p. 516. http://efre2018.hcei.tsc.ru/publication/abstract.html.

26. Gribkov, V.A., Grigor'ev, F.I., Kalin, B.A., and Yakushin, B.L., Perspektivnye radiatsionno-puchkovye tekhnologii obrabotki materialov (Promising RadiationBeam Technologies for Materials Processing), Moscow: Kruglyi God, 2001.

27. Trushin, Yu.V., Fizicheskoe materialovedenie (Physical Materials Science), St. Petersburg: Nauka, 2000.

28. Bystrov, L.N., Ivanov, L.I., and Ustinovschikov, V.M., Radiat. Eff., 1983, vol. 79, p. 63. https://doi.org/10.1080/00337578308207396

29. Shimada, M., Nakahigashi, S., and Terasawa, M., J. Nucl. Sci. Technol., 1976, vol. 13, p. 743. https://doi.org/10.1080/18811248.1976.9734100

30. Isakova, Yu., Prima, A., Zhu, X.P., Ding, L., Zhang, Q., Pushkarev, A., and Lei M.K., Proc. 6th Int. Congress on Energy Fluxes and Radiation Effects (EFRE 2018), Tomsk: Siberian Branch Russ. Acad. Sci., 2018, p. 42. http://efre2018.hcei.tsc.ru/publication/abstract.html.

31. Isakova, Yu.I., Prima, A.I., Pushkarev, A.I., Zhu, X.P., Ding, L., and Lei, M.K., Instrum. Exp. Tech., 2019, vol. 62, no. 2, pp. 201-207.

https://doi.org/10.1134/S002044121901007X
32. Pushkarev, A.I., Isakova, Y.I., Xailov, I.P., and Zhong, H., Rev. Sci. Instrum., 2015, vol. 86, p. 073305. https://doi.org/10.1063/1.4926564

33. Pushkarev, A.I., Isakova, Yu.I., Xiao, Yu., and Khailov, I.P., Rev. Sci. Instrum., 2013, vol. 84, p. 083304. https://doi.org/10.1063/1.4818667

34. Langmuir, I., Phys. Rev., 1913, vol. 2, p. 450.

35. Aston, F.W., Nature, 1920, vol. 105, p. 617.

36. Fleischer, R.L., Price, P.B., and Walker, R.M., J. Appl. Phys., 1965, vol. 36, p. 3645. https://doi.org/10.1063/1.1703059

37. Cartwright, B.G., Shirk, E.K., and Price, P.B., Nucl. Instrum. Methods, 1978, vol. 153, p. 457. https://doi.org/10.1016/0029-554X(78)90989-8

38. Kasuya, K., Watanabe, M., Ido, D., Adachi, T., Nishigoria, K., Ebine, T., Okayama, H., Funatsu, M., Sunami, H., Wu, C., Hotta, E., Miyamoto, S., Yasuike, K., Nakai, S., Kawata, S., Okada, T., and Niu, K., Fusion Eng. Des., 1999, vol. 44, p. 319. https://doi.org/10.1016/S0920-3796(98)00292-0

39. Wiley, W.C. and Maclaren, I.H., Rev. Sci. Instrum., 1955 , vol. 26 , no. 12 , p. 1150. https://doi.org/10.1016/S0920-3796(98)00292-0

40. Mamyrin, B.A., Int. J. Mass Spectrom., 2001, vol. 206, no. 3 , p. 251.

https://doi.org/10.1016/S1387-3806(00)00392-4

41. Wolff, M.M. and Stephens, W.E., Rev. Sci. Instrum., 1953, vol. 24, p. 616.

https://doi.org/10.1063/1.1770801

42. Humphries, S., Charged Particle Beams, New York: Wiley, 1990.

43. Zhu, X.P., Ding, L., Zhang, Q., Isakova, Yu., Bondarenko, Y., Pushkarev, A.I., and Lei, M.K., Laser Part. Beams, 2017, vol. 35, p. 587.

https://doi.org/10.1017/S026303461700060X

44. Paperny, V.L., Chernih, A.A., Astrakchantsev, N.V., and Lebedev, N.V., J. Phys. D: Appl. Phys., 2009, vol. 42, p. 155201. https://doi.org/10.1088/0022-3727/42/15/155201

45. Yushkov, G.Yu., Vodopyanov, A.V., Nikolaev, A.G., Izotov, I.V., Savkin, K.P., Golubev, S.V., and Oks, E.M., Rev. Sci. Instrum., 2014, vol. 85, p. 02B902. https://doi.org/10.1063/1.4824644

46. Furman, E.G., Stepanov, A.V., and Furman, N.Zh., Tech. Phys., 2007, vol. 52, no. 5, p. 621. https://doi.org/10.1134/S1063784207050143

47. Pushkarev, A.I., Isakova, Y.I., and Khaylov, I.P., Nucl. Instrum. Methods Phys. Res., Sect. B, 2015, vol. 343, p. 138. https://doi.org/10.1016/j.nimb.2014.11.021

48. Pushkarev, A., Zhu, X.P., Zhang, C.C., Prima, A., Li, Y., Egorova, Yu., and Lei, M.K., Rev. Sci. Instrum., 2019, vol. 90, p. 103303.

https://doi.org/10.1063/1.5116598

49. Renk, T.J., Schall, M., and Cooper, G.W., Sandia Report SAND2009-8165, 2009.

https://pdfs.semanticscholar.org/8a81/6af20a5eae799e88 f9403a8da9d38d241f6b.pdf. 
50. Morozov A.I., Introduction to Plasma Dynamics. Cambridge International Science Publishing, Limited, 2010.

51. Bugaev, S.P., Krendel', Yu.E., and Shanin, P.M., Elektronnye puchki bol'shogo secheniya (Electron Beams with Large Cross-Section), Moscow: Energoatomizdat, 1984.

52. Moskalev, V.A. and Sergeev, G.I., Izmerenie parametrov puchkov zaryazhennykh chastits (Measurement for Parameters of Charged Particles Beams), Moscow: Energoatomizdat, 1991.

53. Egorov, I., Serebrennikov, M., Isakova, Yu., and Poloskov, A., Nucl. Instrum. Methods Phys. Res., Sect. A, 2017, vol. 875, p. 132.

https://doi.org/10.1016/j.nima.2017.09.002

54. Lipchak, A.I., Mikhailov, S.G., and Solomonov, V.I., Instrum. Exp. Tech., 1997, vol. 40, no. 2, p. 219.

55. Solomonov, V.I. and Mikhailov, S.G., Impul'snaya katodolyuminestsentsiya i ee primenenie dlya analiza kondensirovannykh veshchestv (Pulse Cathodoluminescence and its Application for Analyzing Condensed Substances), Yekaterinburg: Ural Branch Russ. Acad. Sci., 2003.

56. Generalova, V.V. and Gurskii, M.N., Dozimetriya v radiatsionnoi tekhnologii (Dosimetry for Radiation Technology), Moscow: Izd. Standartov, 1981.

57. Sokovnin, S.Yu., Nanosekundnye uskoriteli elektronov dlya radiatsionnykh tekhnologii (Nanosecond Electron Accelerators for Radiation Technologies), Yekaterinburg: Ural State Agrarian Univ., 2017.

58. https://www.originlab.com.

59. Pushkarev, A., Kholodnaya, G., Sazonov, R., and Ponomarev, D., Rev. Sci. Instrum., 2012, vol. 83, no. 10, p. 103301. https://doi.org/10.1063/1.4756689

60. Ozur, G.E. and Proskurovskii, D.I., Istochniki nizkoenergeticheskikh sil'notochnykh elektronnykh puchkov s plazmennym anodom (Sources of Low-Energy HighCurrent Electron Beams with Plasma Anode), Novosibirsk: Nauka, 2018.

61. Kiziridi, P.P. and Ozur, G.E., Tech. Phys., 2015, vol. 60, no. 6, p. 917. https://doi.org/10.1134/S1063784215060110

62. Voisin, L., Bicrel, B., Desanlis, T., Galtié, A., Hebert, D., Lasserre, J.P., Loreau, Y., Serrand, A., Noel, C., and Pierret, O., Proc. 3rd Euro-Asian Pulsed Power Conference/ 18th Int. Conference on High-Power Particle Beams, Korea Electrotechnology Research Institute, 2010, p. 104.

63. Remnev, G.E., Furman, E.G., Pushkarev, A.I., Karpuzov, S.B., Kondrat'ev, N.A., and Goncharov, D.V.,
Instrum. Exp. Tech., 2004, vol. 47, no. 3, pp. 394-398. https://doi.org/10.1023/B:INET.0000032909.92515.b7

64. https://www.fluke.com.

65. Bespalov, V.I., Vzaimodeistvie ioniziruyushchikh izluchenii s veshchestvom. Uchebnoe posobie (Interaction between Ionizing Radiation and Matter. Student's Book), Tomsk: Tomsk Polytechnic Univ., 2007.

66. Lyamshev, L.M., Radiatsionnaya akustika (Radiation Acoustics), Moscow: Nauka, 1996.

67. White, R.M., J. Appl. Phys., 1963, vol. 34, p. 3559. https://doi.org/10.1063/1.1729258

68. Zalyubovskii, I.I., Kalinichenko, A.I., and Lazurik, V.T., Vvedenie $v$ radiatsionnuyu akustiku (Interaction into Radiation Acoustics), Kharkov: Kharkov State Univ., Vishcha Shkola, 1986.

69. Batygin, Yu.V., Volovik, V.D., Ivanov, S.I., and Karasev, S.P., Prib. Tekh. Eksp., 1980, no. 4, p. 24.

70. Volovik, V.D. and Ivanov, S.I., Zh. Tekh. Fiz., 1975, no. 8, p. 1789.

71. Pushkarev, A., Isakova, J., Kholodnaya, G., and Sazonov, R., Sound waves generated due to the absorption of a pulsed electron beam, in Advances in Sound Localization, Vienna: INTECH, 2011, Chap. 12, p. 199. https://doi.org/10.5772/15273

72. Dong, Z.H., Liu, C., Han, X.G., and Lei, M.K., Surf. Coat. Technol., 2007, vol. 201, p. 5054. https://doi.org/10.1016/j.surfcoat.2006.07.149

73. Zhu, X.P., Zhang, F.G., Tang, Y., Xin, J.P., and Lei, M.K., Nucl. Instrum. Methods Phys. Res., Sect. B, 2012, vol. 272, p. 454. https://doi.org/10.1016/j.nimb.2011.01.122

74. Zhu, X.P., Lei, M.K., Dong, Z.H., and Ma, T.C., Rev. Sci. Instrum., 2003, vol. 74, p. 47. https://doi.org/10.1063/1.1529303

75. Boiko, V.I., Daneikin, Yu.V., Khadkevich, A.V., and Yushitsin, K.V., Izv. Tomsk. Politekh. Univ., 2007, vol. 310, no. 2, p. 82.

76. Pushkarev, A.I., Isakova, Yu.I., and Khaylov, I.P., Laser Part. Beams, 2014, vol. 32, p. 311. https://doi.org/10.1088/1742-6596/511/1/012073

77. Zhu, X.P., Ding, L., Zhang, Q., Pushkarev, A.I., and Lei, M.K., Instrum. Exp. Tech., 2017, vol. 60, no. 4, pp. $562-569$.

https://doi.org/10.1134/S0020441217030277

Translated by A. Seferov 